\title{
X-ray standing wave analysis for bromine chemisorbed on silicon
}

\section{Citation}

Bedzyk, M.J., Gibson, W.M., Golovchenko, A. 1982. X-Ray Standing Wave Analysis for Bromine Chemisorbed on Silicon. Journal of Vacuum Science and Technology 20, no. 3: 634-637. doi:10.1116/1.571412.

\section{Published Version}

doi:10.1116/1.571412

\section{Permanent link}

http://nrs.harvard.edu/urn-3:HUL.InstRepos:29407053

\section{Terms of Use}

This article was downloaded from Harvard University's DASH repository, and is made available under the terms and conditions applicable to Other Posted Material, as set forth at http:// nrs.harvard.edu/urn-3:HUL.InstRepos:dash.current.terms-of-use\#LAA

\section{Share Your Story}

The Harvard community has made this article openly available.

Please share how this access benefits you. Submit a story.

Accessibility 


\title{
X-ray standing wave analysis for bromine chemisorbed on silicon
}

\author{
M. J. Bedzyk and W. M. Gibson
}

Institute for Particle Solid Interactions, Physics Department, State University of New York at Albany, 1400 Washington Avenue, Albany, New York 12222

\section{J. A. Golovchenko}

IE-439, Bell Laboratories, 600 Mountain Avenue, Murray Hill, New Jersey 07974

(Received 24 September 1981; accepted 5 November 1981)

$X$-ray standing wave measurements on single crystals of silicon are used to determine the coverage and position of chemisorbed bromine. Detailed analysis of the position information leads to the conclusion that silicon surface atoms bonded to adsorbed bromine atoms are in extrapolated bulk-line positions. Direct measurement of the desorption of correlated bromine in air demonstrates the high stability of the $\mathrm{Br} / \mathrm{Si}$ surface interface.

PACS numbers: 68.45.Da, 63.10.Dp, 61.70.Wp, 78.70.Ck

\section{INTRODUCTION}

The $x$-ray standing wave technique developed by J. A. Golovchenko et al. has been used successfully in the past for studying the impurity correlated positions interior and exterior to the surfaces of single crystals. The interior case study was for arsenic atoms implanted and annealed to substitutional positions in silicon. ${ }^{1}$

The exterior case study made use of the highly penetrating power of $x$-rays by measuring through a thin layer of methanol the correlated position of bromine atoms chemisorbed on Si (220) at the solid-liquid interface. ${ }^{2}$ This $\mathrm{Br} / \mathrm{Si}$ interface has proven to be an extremely stable system for non UHV analysis. ${ }^{3}$ It is the intentions of this $x$-ray standing wave study to quantitatively measure the stability of this interface in terms of its open air desorption rate. Also to be reported are preliminary results for the ultraviolet photon induced $\mathrm{Br}$ adsorption on the Si (220) surface and a surface structure characterization of the $\mathrm{Br} / \mathrm{Si}(111)$ interface.

\section{EXPERIMENTAL}

Prior to $\mathrm{Br}$ deposition a $2 \times 2 \times 0.5 \mathrm{~cm}$ Si sample was Syton polished and etched in hydroffuoric acid. The sample was then passed in an argon atmosphere from the HF etch to a methanol rinse and then to a $0.05 \%$ by volume $\mathrm{Br}$ methanol solution. While in the $\mathrm{Br}$ methanol bath the surface was exposed for $\sim 5 \mathrm{~min}$ to uv light through a thin film of the solution. The uv source used was a 140 -W low-pressure mercury vapor lamp with a quartz envelope. Following the uv $\mathrm{Br}$ methanol treatment four rinses in methanol were used to remove any excess $\mathrm{Br}$. The sample was then blown dry in argon prior to the open air $x$-ray standing wave measurement.

For $x$-ray standing wave analysis a single crystal sample is placed in the second position of a double crystal spectrometer (Fig. 1). In the first crystal position an asymmetrically cut single crystal is used to collimate and monochromate the $k \alpha \mathrm{x}$-rays of a molybdenum fine focus $\mathrm{x}$-ray tube $(\lambda=0.709$ A). As predicted by the dynamical theory of $x$-ray diffraction $^{4}$ a well defined standing wave field is produced at the second crystal when the collimated incident beam is Bragg diffracted (Fig. 2). The standing wave pattern is parallel to and has the same spacing as the Miller planes being used by both crystals for diffraction. The standing wave field extends thousands of angstroms out from the surface of the second crystal. Proper alignment of the two crystals is monitored by the angular reflectivity response of a $\mathrm{NaI}$ detector (Fig. 1). Currently there are a number of single crystalline materials available with mosaic spreads low enough for producing natural reflectivity curve shapes. Any of these single crystals can be used for producing a well defined $\mathrm{x}$-ray standing wave field.

Advancing in angle through the strong Bragg diffraction region causes a gradual phase change of $\pi$ for the amplitude of the diffracted electric field with respect to the amplitude of the incident electric field. This phase change causes the antinodes of the standing wave field to move from midway between the Miller diffracting planes to a position coincident with them. Advancing from the low angle side of the strong diffraction region to the high angle side results in increased absorption as the $x$-ray standing wave field antinodes approach the crystal planes. This anomalous effect accounts for the slightly nonsymmetrical shape of the refectivity curve shown in Fig. 3. Also depicted in Fig. 3 are the x-ray field intensities for various test positions plotted as a func-

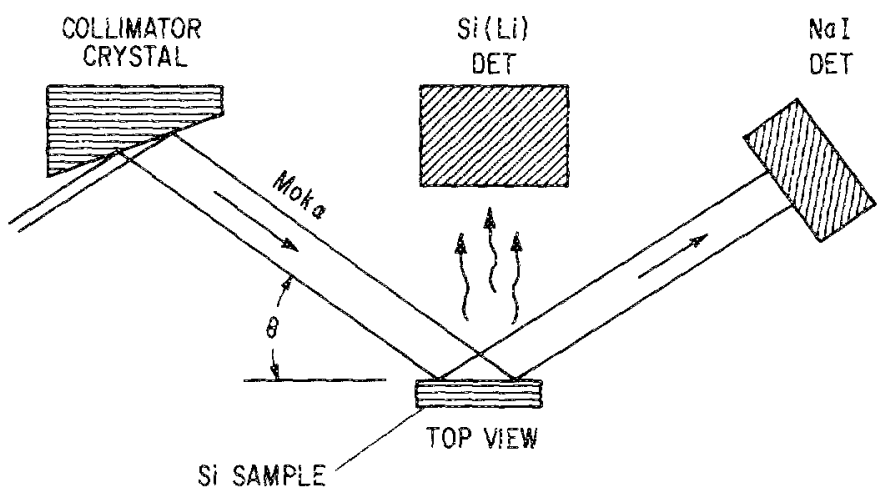

FIG. 1. Schematic layout of experimental apparatus. 


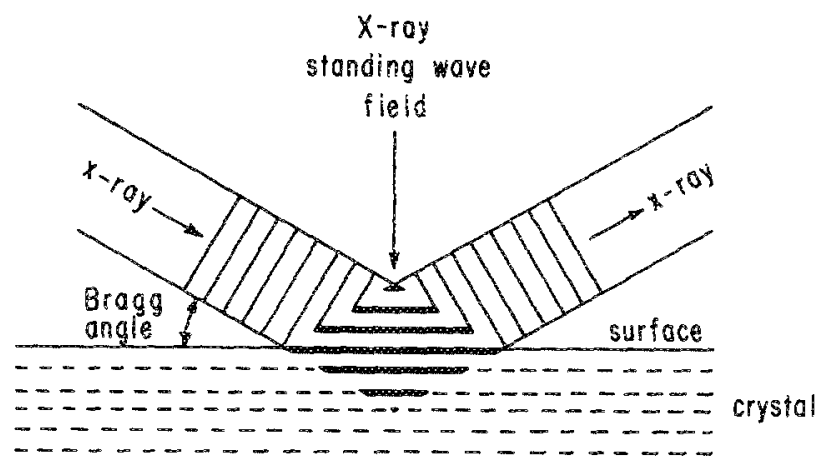

FIG. 2. Illustration of an $x$-ray standing wave field formed by Bragg diffraction.

tion of angle.

The inelastic interaction of the x-ray standing wave field with impurity atoms located at a particular position can be used to determine the position of these atoms relative to the diffraction planes which are generating the standing wave pattern. This positional determination is possible since the fuorescence yield from these impurity atoms is proportional to the $\mathrm{x}$-ray field intensity at the impurity atom position. In our present study a $\mathrm{Si}(\mathrm{Li})$ detector (Fig. 1) is used to measure $\mathrm{Br} k \alpha$ fuorescence as the sample crystal is rocked back and forth across the Bragg reflectivity region. By monitoring the $\mathrm{Br}$ fuorescence yield, as a function of the relative angle between the two crystals, it is possible to determine if any sig-

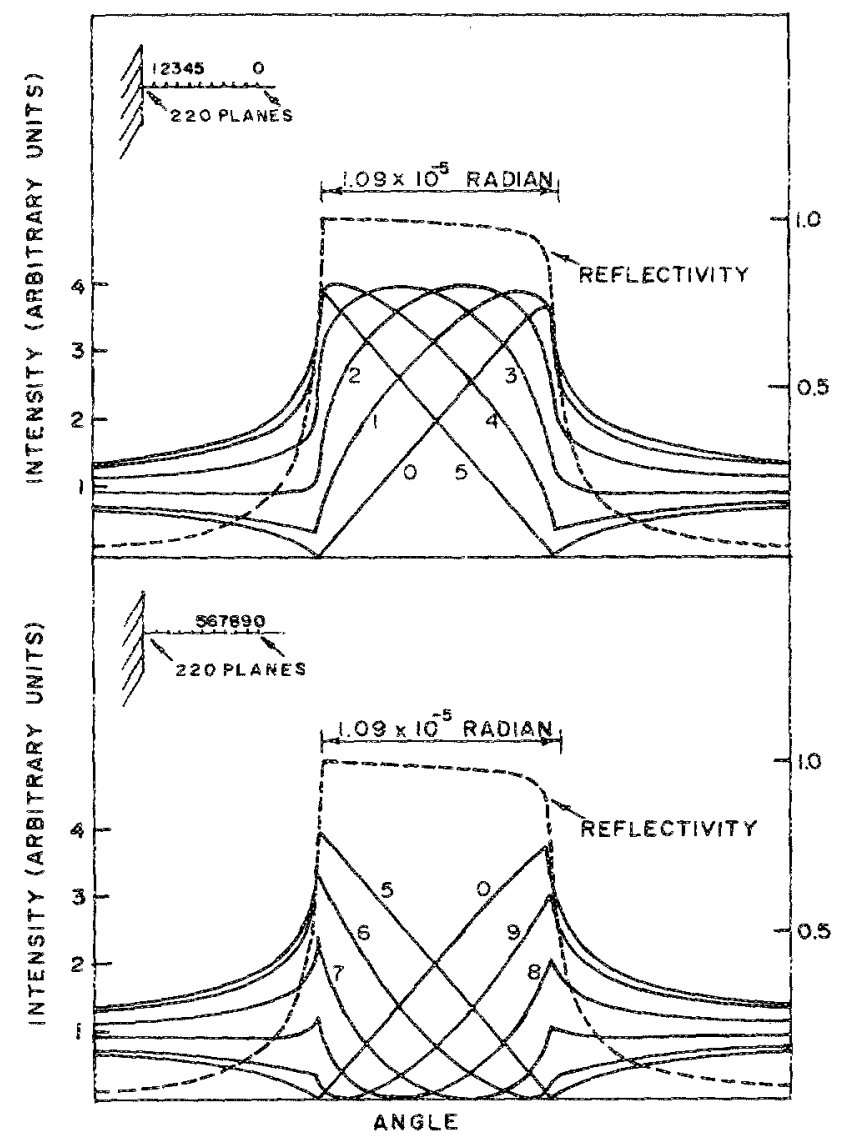

FIG. 3, - $\mathrm{x}$-ray held intensities at extended 220 lattice positions $(0-9)$ for a perfectly collimated incident beam. o..-Bragg reflectivity for a perfectly collimated incident beam. nificant fraction of the $\mathrm{Br}$ atoms are positionally correlated.

For the $\mathrm{Br} / \mathrm{Si}$ surface interface $\mathrm{Br}$ atoms are either randomly distributed (random) or take up specific preferred positions relative to the substrate difraction planes (correlated) or a combination of these. For structure analysis the $\mathrm{Br}$ fuorescence yield is compared to various test position field intensity patterns (Fig. 3) variably combined with a random intensity pattern. The best fit yields the correlated position $\left(P_{C}\right)$ and the fraction of $\mathrm{Br}$ atoms which are correlated (correlated fraction $\left.F_{C}\right)$. The total $\mathrm{Br}$ coverage $\left(\theta_{T}\right)$ is determined, to within a few percent, by comparing the of Bragg fuorescence yield of the chemisorbed sample to that of a standard $\mathrm{Br}$ implanted sample. The correlated coverage $\left(\theta_{C}\right)$ is then defined as the correlated fraction of the total Br coverage.

It should be noted that the correlated position for chemisorbed surface atoms is measured relative to the bulk extrapolated Si surface plane. Due to the possibility for Si surface relaxation and reconstruction, the surface plane extrapolated from the bulk and the actual Si surface may not coincide.

\section{RESULTS AND DISCUSSION}

For a Si (220) sample prepared as previously described, an $x$-ray standing wave analysis (Fig. 4) concluded that $37 \%$ of the $0.29 \pm 0.03$ monolayers of $\mathrm{Br}$ atoms on the $\mathrm{Si}(220$ ) surface were correlated to a substrate-like fractional position of $0.93 \pm 0.02$. This open air result agrees well with the previously published methanol solid-liquid interface result. ${ }^{2}$ Therefore any positional pertubation due to the methanol is less than the $\pm 0.04 \AA$ error. This open air positional measurement also agrees well with a simple model (Fig. 5), in which the surface Si atoms are assumed to have substratelike positions and dangling bond directions. These are bonded covalently to Br atoms with a $\mathrm{Si}-\mathrm{Br}$ bond length equiv-

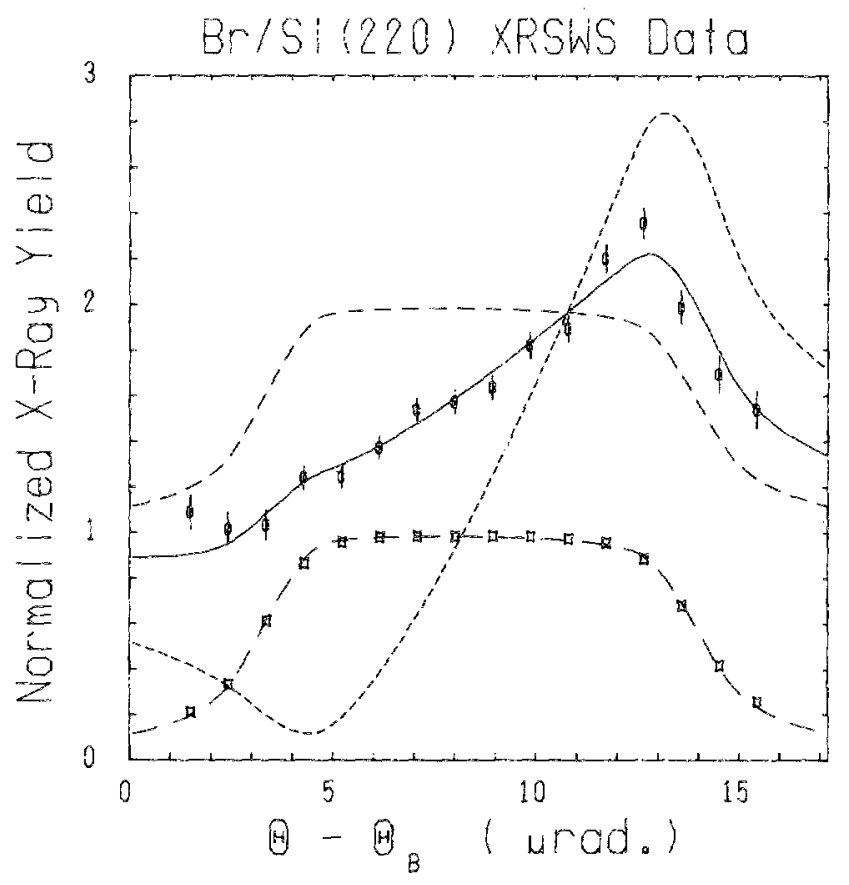

FrG. 4. $\phi$ Br fluorescence data; $\square$ reflectivity data;-- Theoretical Bragg reflectivity; --. Random Theoretical yield; - - 100\% correlated at $P_{C}=0.93$ theoretical yield; - $37 \%$ correlated at $P_{C}=0.93$ theoretical yield. 


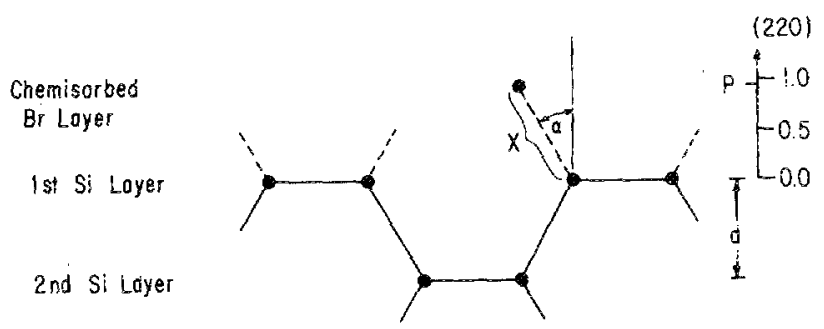

FiG. $5 . \mathrm{Br} / \mathrm{Si}(220)$ substrate-like surface model $d=1.92 \AA, X=2.17 \AA$, $\alpha=35.3^{\circ}, P=0.92$.

alent to that found in $\mathrm{SiBr}_{4}$. This model predicts a substratelike fractional position of 0.92 . The excellent agreement between this prediction and the $\mathrm{x}$-ray standing wave result is not in itself proof that all of the assumptions made in this model are correct, since the $\mathrm{Br}$ positional prediction of this model is made with respect to the Si surface atomic plane, while the measured result is relative to the bulk extrapolated Si surface plane. However, from electron scattering results on various silicon bromine volatile molecules, ${ }^{5}$ the length and angle of the $\mathrm{Si}-\mathrm{Br}$ bond is known to be relatively insensitive to its neighboring environment. Therefore the only unsubstantiated assumption made in this model is that the $\mathrm{Si}$ surface atomic layers are bulk-like. In view of the constancy of the Si-Br covalent bond, the $\mathrm{X}$-ray standing wave measurement shows that at the $\mathrm{Br} / \mathrm{Si}(220)$ interface the surface $\mathrm{Si}$ atoms bonded to adsorbed $\mathrm{Br}$ are in bulk-like positions to within $\pm 0.04 \AA$. Data taken for the adsorption of hydrogen on Si (Ref. 6) also show that when dangling surface Si bonds are saturated the surface layers relax back toward bulk-like positions.

A similar surface structure model for $\mathrm{Br} / \mathrm{Si}$ (111), in which the dangling bonds are normal to the surface, predicts a Br substrate-like fractional position of 0.815 . Analysis of $x-$ ray standing wave data, ${ }^{7}$ that will be published at a later date, agrees with this prediction, substantiating the above conclusion that the Si surface atoms are bulk-like.

Due to the low counting rate for submonolayer coverages of $\mathrm{Br}$, long time periods of angular scanning are required to accumulate sufficient spectroscopic data in the 16 angular regions of the scan. For example, the spectroscopic scan data illustrated in Fig. 4 required thirteen hours of measurements.

Based on a number of angular scan experiments the correlated positional measurement of 0.93 has proven to be a reliable quantity. Therefore it was used as an assumed value for doing half hour measurements of the correlated coverage $\left(\theta_{C}\right)$. These measurements were performed by monitoring the $\mathrm{Br}$ fluorescence yield at only two of the previously 16 angular positions. For reasons of contrast and control the positions were taken on the two sides of the reffectivity curve, the low absorption edge and the high absorption edge. This type of a measurement will be referred to as a high/low measurement. The time development for correlated $\mathrm{Br}$ coverage is depicted in Fig. 6 . These data show a desorption rate $\left(k_{D}\right)$ proportional to the correlated coverage $\left(\theta_{C}\right)$ :

$$
\theta_{C}=\theta_{C, 0} e^{--k_{B^{t}}}
$$

where $k_{D}=0.050 \mathrm{~h}^{-1}$. It is convenient in such an exponential decay curve to characterize the decay rate in terms of a decay time (half-life) which in the present case is $14 \mathrm{~h}$. The $\mathrm{Br} / \mathrm{Si}(111)$ interface has also shown an extremely long decay time in open air.

High/low measurements were also performed to study the effect of uv light used in the previously described sample preparation. The preliminary results indicate that samples prepared in such a manner have at least two times the amount of correlated $\mathrm{Br}$ as control samples which were prepared in the dark. A more complete photochemical analysis will be published at a later date.

\section{CONCLUSIONS}

Since the correlated $\mathrm{Br}$ coverage is submonolayer and the $\$ i$ (Li) detector used in this open air analysis is unable to detect oxygen and hydrocarbons, the actual complexity of the $\mathrm{Br} / \mathrm{Si}$ surface interface is not completely clear from these measurements. It is possible that $x$-ray induced Auger emission from such surfaces in a vacuum can provide additional

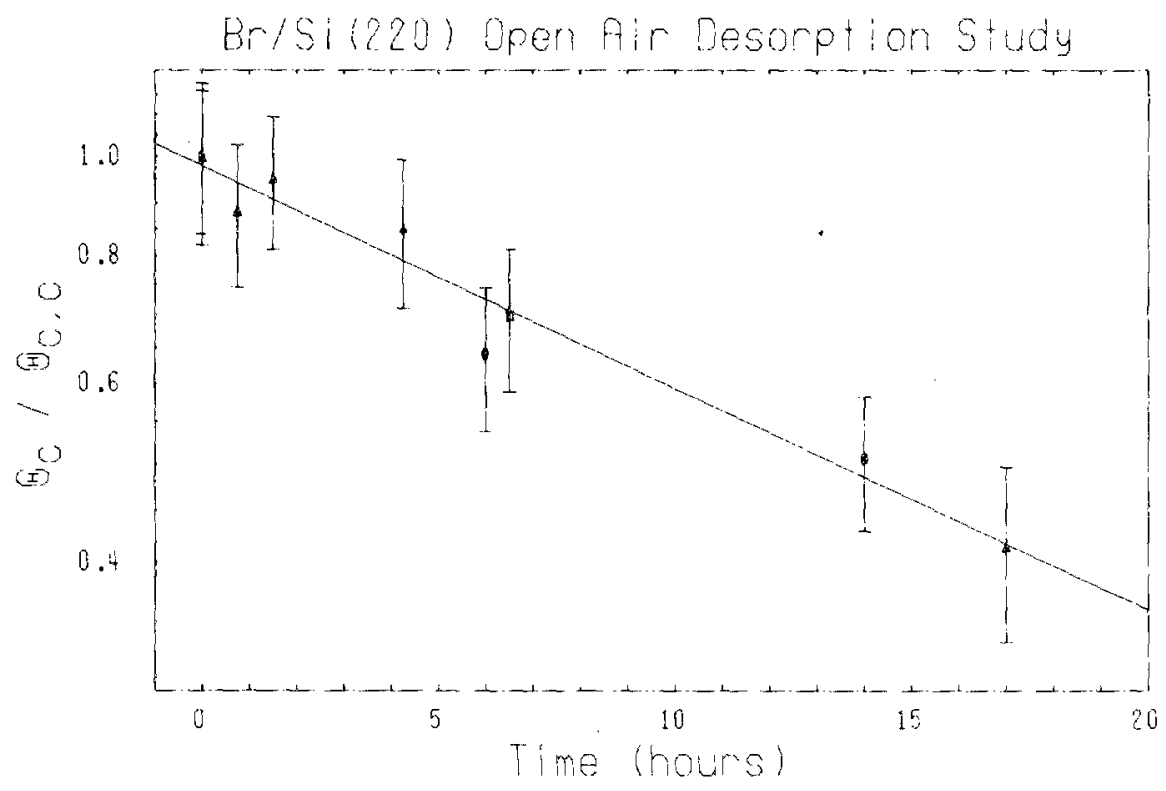

FIG. 6. Time development of correlated $\mathrm{Br}$ coverage $\left(\theta_{C}\right)$ relative to the initial correiated $\mathrm{Br}$ coverage $\left(\theta_{C, 0}\right)$. $\square$ value from $13 \mathrm{~h}$ scan of Fig. 4; $\Phi$ from high/low measurements taken during scan; from a subsequent high/low analysis. 
information. However, the ability of the $x$-ray standing wave technique to make high resolution measurements on open air or in situ interfaces leads to some unique results.

The existance of $\mathrm{Br}$ atoms correlated to substrate-like positions is evidence for a certain degree of order at the $\mathrm{Br} / \mathrm{Si}$ interface, and the extremely long half-life for correlated $\mathrm{Br}$ atoms at this open air interface shows its stability.

The effect that this interface may have on oxidation is also of interest and presentiy is being studied by $x$-ray standing wave analysis combined with ion backscattering/channeling experiments.

Future plans for joining the $\mathrm{x}$-ray standing wave technique to a synchrotron $x$-ray source will greatly enhance the ability for doing time developed desorption and $u v$ induced adsorption experiments.

\section{ACKNOWLEDGMENTS}

The authors are grateful for the assistance given by $A$. Haber, C. Pauley, B. Krawchuk, R. Stamp, and K. Webster of SUNYA, P. Freeland and J. R. Patel Bell Laboratories, and P. L. Cowan of NBS. The financial support of the Office of Naval Research, under contract No. 00014-78-C-0616, is also acknowledged.

'(a) J. A. Goloychenko, B. W. Batterman, and W. L. Brown, Phys. Rev. B 10,4239(1974). (b) S. K. Anderson, J. A. Golovchenko, and G. Mair, Phys. Rev. Lett. 37, 1141 (1976)

2P. L. Cowan, I. A. Golovchenko, and M. F. Robbins, Phys. Rev. Lett. 44 $1680(\$ 980)$.

${ }^{3}$ D. E. Aspnes and A. A. Studna, Soc. Photo-Opt. Instrum. Eng. 276, 227 (1981)

${ }^{4}$ M. Y. Laue, Ann. Physik 23, 705 (1935).

${ }^{5}$ Halogen Chemistry, edited by Viktor Gutmann (Academic, New York, 1967), Vol. 2

(a) R. M. Tromp, R. G. Smeenk, and F. W. Saris, Phys. Rev. Lett. 46, 939 (1981); (b) T. Narusawa, K. Kinoshita, W. M. Gibson, and L. C. Feldman (to be published).

'M. J. Bedzyk, P. L. Cowan, J. A. Golovchenko, and D. Kaplan to be published!. 